\title{
A criança e o professor na Educação Infantil: representações de alunos do curso de Pedagogia
}

\author{
Célia Maria Guimarães* \\ Sílvia Adriana Rodrigues** \\ Claudia Cristina Garcia Piffer ${ }^{* * *}$
}

\section{Resumo}

Tendo como aporte teórico a teoria das Representações Sociais (RS) de Moscovici e seguidores, pretendemos investigar a interferência dos processos de formação inicial nas representações que os futuros professores têm e constroem sobre o trabalho pedagógico na Educação Infantil. Adotamos como objetivos específicos: identificar junto aos alunos em formação no curso de Pedagogia da FCT/Unesp e do CPAN/UFMS como se estruturam as representações sociais sobre a profissão docente, sobre a especificidade do trabalho pedagógico e sobre as crianças com as quais exercerão a docência; analisar continuidades e transformações nas RS no decorrer do processo de formação inicial, procurando identificar se o processo formativo e as práticas educativas adotadas são capazes de imprimir alterações nas RS preexistentes e comparar as representações dos estudantes. O estudo, de caráter longitudinal, acompanhará os estudantes entre os anos de 2009 e 2012, utilizando como instrumentos para obtenção dos dados questionários, texto narrativo e entrevistas. O tratamento dos dados se deu com auxílio de softwares estatísticos (Evoc, Alceste e SPSS) e da análise de conteúdo (BARDIN, 1977). Encontramos RS entre os estudantes das duas universidades que não se adequam ao perfil de professor de crianças pequenas e a concepção de criança/infância na contemporaneidade.

Palavras-chave: representações sociais; Educação Infantil; formação de professores.

\section{The child and the teacher in Early Childhood Education: representations of Pedagogy students}

\section{Abstract}

Taking Moscovici and his follower $\hat{\mathbf{s}}$ social representations (SR) theory as support we intend to investigate the interference of initial formative processes in the representations that future professional teachers have and build on the pedagogical work in early childhood education. We adopt as specific goals: to identify how

\footnotetext{
* Professora Doutora da Universidade Estadual Paulista (Unesp). Vila Maristela, São Paulo, Brasil.

** Professora da Universidade Federal do Mato Grosso do Sul (UFMS), Corumbá, Mato Grosso do Sul, Brasil.

*** Professora da Universidade Estadual Paulista (Unesp), Presidente Prudente, São Paulo, Brasil.
} 
the social representations about the teaching profession, the specificity of the pedagogical work and the children to whom they will be teaching are structured by the students in the Early Childhood Program of the School of Education at FCT/Unesp and at CPAN/UFMS; to analyze continuities and transformations in social representations (SR) during their preservice education, seeking to identify if the formative process and the educative practices adopted can cause changes in the previously existing SR; and to compare the studentsôrepresentations. The study, of a longitudinal characteristic, will follow the students between the years 2009 and 2012, using questionnaires, narrative text and semi-structured interviews as instruments for data collection. The data will be processed with the aid of statistical software (EVOC, Alceste and SPSS) and according to the technique of content analysis (BARDIN, 1977). We found among the students from the two universities SR that do not suit either the young children teacher profile or the commonly accepted concept of the child/childhood in contemporary society.

Keywords: social representations; Children Education; teacher formation.

\section{Introdução}

O trabalho ora apresentado é substrato de um estudo que vem sendo desenvolvido no âmbito de um projeto maior do Centro Internacional de Estudos em Representações Sociais e Subjetividade-Educação (CIERS-Ed/Fundação Carlos Chagas/SP), com o objetivo de investigar as representações sociais do futuro professor sobre o trabalho docente. Esta pesquisa é organizada de forma a possibilitar a comparação dos dados de duas regiões brasileiras e, ao mesmo tempo, permitir que cada grupo investigue problemas específicos de seu interesse.

Buscamos também investigar se as representações de professoras ${ }^{1}$ de crianças pequenas estão contempladas no perfil de professor e no modelo de escola, implícitos nas representações dos estudantes de Pedagogia.

A presente pesquisa, desenvolvida por três pesquisadoras de duas universidades de dois Estados brasileiros, apoia-se na Teoria das Representações Sociais de Moscovici, na Teoria do Núcleo Central de Abric e em referenciais da Educação Infantil (EI). Tem como pressupostos iniciais que as funções tradicionalmente atribuídas às creches e pré-escolas e as imagens normalmente atribuídas à criança exercem uma função organizadora das RS de trabalho da professora de El; tem como sujeitos 107 estudantes ingressantes nos cursos de Pedagogia de universidades públicas de dois Estados brasileiros: 68 da Unesp e 39 da UFMS. ${ }^{2}$

Os pressupostos iniciais que orientaram essa etapa da pesquisa são que as funções tradicionalmente atribuídas às creches e pré-escolas e os significados conferidos à criança exercem uma função organizadora das Representações Sociais de trabalho da professora de El. 
Assim, tendo em vista a especificidade da $\mathrm{El}$, as palavras indutoras para a técnica de associação livre foram delimitadas em seis: criança, creche, pré-escola, professor, afetividade e família. O processo de coleta de dados também abrangeu questionários. ${ }^{3} \mathrm{O}$ questionário-perfil totaliza 23 questões, divididas em 14 questões gerais e 9 específicas.

O questionário-carta contemplou aspectos como: desenvolvimento versus preparação para a escola; doméstico versus profissional; cuidado versus educação, além dos elementos que marcam a especificidade da profissão, totalizando 28 questões.

O levantamento de dados da primeira etapa junto aos estudantes da Pedagogia da Unesp, e UFMS, ingressantes em 2009, aconteceu no início do primeiro bimestre letivo de 2009.

\section{Alguns pressupostos do estudo}

A LDB, ao inserir as creches e pré-escolas no sistema de ensino oficial, gerou a necessidade da formação específica do professor da El, além de salientar que o atendimento prestado à criança, na instituição de EI (IEI), exige a articulação entre a educação da criança e os seus cuidados. Tal afirmação nos remete imediatamente para o problema do papel social dessa instituição, o qual se encontra ainda hoje em processo de (in)definição, reforçada pelo distanciamento entre o que preconiza a legislação e as ações cotidianas.

A formação inicial do professor de crianças pequenas se encontra atualmente diante de possibilidades e riscos, mormente perante $\mathrm{o}$ atendimento à exigência do disposto na Resolução CNE/CP01/2006, ${ }^{4}$ que fixou novas Diretrizes Curriculares para os projetos de formação do professor nos cursos de Pedagogia.

Cabe dizer que a Resolução do CNE, pela precária fundamentação teórica quanto ao campo conceitual da Pedagogia, pelas imprecisões conceituais e pela desconsideração dos vários âmbitos de atuação científica e profissional do campo educacional, sustenta-se numa concepção simplista e reducionista da Pedagogia e do exercício profissional do pedagogo, o que pode vir a afetar a qualidade da formação de professores de El e anos iniciais.

Assim, os projetos de formação dos cursos de Pedagogia se veem diante de uma visão de criança e de um tipo de creche e pré-escola que se distancia da ideia de assistência ou de caricatura do Ensino Fundamental, impondo um perfil de professora que precisará saber como interagir com sujeitos em desenvolvimento e crescimento, nos ambientes coletivos da creche e da pré-escola. ${ }^{5}$

Assumir a concepção de El como espaço educativo e de cuidados da criança pequena remete-nos à realidade brasileira, em que cuidar e educar de 
crianças pequenas é pouco valorizado socialmente. Para Machado (1999, p. 85), a concepção de integração cuidar/educar com rã proposta da Pedagogia das interações [...] vem tentando romper com modos tradicionais de organização da prática pedagógica nas instituições de Elò Oliveira-Formosinho et al. (2007) propõem uma Pedagogia que se centra nas crianças, que cria espaço para sua participação, com base em uma estrutura, em recursos e em interações intencionalmente pensados, de modo que a escuta ativa da criança tenha reais consequências nos resultados de aprendizagem.

Inspiradas pelas argumentações anteriores, nesta pesquisa, consideramos que a abordagem das representações sociais, durante o processo formativo de professores, fecunda e articula a elaboração da identidade da creche e da pré-escola como espaço educativo capaz de favorecer a construção da identidade de professora de crianças pequenas.

A imagem, as crenças, as expectativas que foram elaboradas sobre $o$ que/como é ser professora de crianças pequenas, na creche e na pré-escola, são ativadas quando o estudante pode participar de metodologias formativas que promovem a interação com as crianças, no contexto da instituição de $\mathrm{El}$, a partir de finalidades claras. Suas representações sociais, suas ideias-imagens de professora de crianças pequenas e do trabalho pedagógico naqueles espaços orientarão seus primeiros contatos com a realidade concreta; a criança real, as contradições e a variabilidade do dia a dia orientarão (re)ações, escoIhas e suscitarão certas motivações, conflitos, certezas e dúvidas.

Baillauquès (2001) ressalta que resultados de estudos tendem a demonstrar que considerar as representações sociais contribui para a profissionalização docente, no percurso de sua evolução. Explica que trabalhar com as representações serve primeiramente para sensibilizar em relação ao trabalho docente, reconhecer suas motivações, tendo como referência sua adequação à realidade profissional, aos espaços onde exercerá a docência.

Assim, estudar as representações sociais que futuros professores de El elaboraram sobre a profissão de professora é um meio de avaliarmos como temos realizado a formação inicial na universidade.

Depreende-se ainda que investigar as RS que os futuros professores de crianças pequenas têm da creche e da pré-escola pode também contribuir para a construção de um outro paradigma de formação inicial do professor da El, apoiado pela compreensão das motivações e resistências. As RS iniciais dos estudantes, bem como suas transformações e/ou permanências, no decorrer da formação inicial, poderão nos orientar na escolha de processos que verdadeiramente nos permitam contribuir, como formadores, para a elaboração de uma outra compreensão da criança pequena e da função da professora, a partir da revisão das crenças sobre a creche/pré-escola e da função da creche e préescola em vigor. 
Desse modo, os resultados que apresentaremos se traduzem num recorte do estudo longitudinal mencionado e abordarão a parte da investigação que tem como objeto as representações de ingressantes do curso de Pedagogia sobre o trabalho da professora da El (0-5 anos), a partir das respostas dos estudantes da Unesp ${ }^{6}$ e da UFMS. ${ }^{7}$

\section{As representações sociais dos estudantes sobre ser professor(a) de crian- ças pequenas}

A opção metodológica desta investigação se fundamenta numa abordagem qualitativa e contém nuanças de um estudo longitudinal. Propõe-se acompanhar os estudantes entre os anos de 2009 e 2012, período da sua formação inicial, com o intuito de conhecer as RS sobre ser professora de crianças pequenas que os estudantes em formação podem ter, em diferentes momentos de sua graduação. Teremos em vista os conhecimentos que detinham previamente ao processo de formação inicial e as transformação/mudanças conseguidas ao final do processo. A obtenção dos dados que ora serão expostos ocorreu logo nas duas primeiras semanas de aula do ano letivo de 2009. Nas últimas semanas que antecederem a conclusão da graduação, em 2012, outro questionário será aplicado a todos os alunos. A pesquisa conta ainda com a elaboração de textos narrativos (REIS, 2008), e entrevistas semiestruturadas (SZYMANSKI, 2001), realizadas com uma amostra dos participantes, ao final do segundo e terceiro ano de curso.

Os resultados em discussão foram obtidos por meio do tratamento das respostas feitos no programa EVOC 2000 (Ensemble de Programmes Permettant Läannalyse des Evocations, de Vergés, versão 2002) para as questões de associação livre com a palavra indutora ï professor. A análise dos dados, orientada pela abordagem estrutural de estudos de representações sociais, priorizou, por meio do citado software, a identificação dos conteúdos e da estrutura da representação social. Para o tratamento das questões abertas, selecionadas do total de questões do instrumento, utilizamos o software SPSS e a técnica de análise de conteúdo (BARDIN, 1977).

Cabe salientar que as questões abertas selecionadas para este texto nos permitem examinar as preferências pelo campo de trabalho, expectativas/satisfação e motivação pela futura profissão, além das referências que as futuras professoras pensam em utilizar, a fim de desenvolver o trabalho de professora de crianças pequenas. A exposição que se segue foi organizada trazendo a caracterização dos estudantes participantes, seguida da análise dos dados que apresentam o núcleo central das RS sobre professor e análise de algumas questões abertas.

Assim, no que diz respeito ao perfil dos estudantes, a análise dos dados demonstrou tendências, quais sejam: a grande maioria é do sexo feminino; os estudantes da Unesp são mais jovens ï a maioria tem entre 17 e 20 anos ï , enquanto que os alunos da UFMS, metade se encontra nessa faixa etária e 
outra metade tem entre 21 e 30 anos. Sobre a situação civil, nos dois grupos, temos a maioria de solteiros, sem filhos; em ambos os grupos, a grande maioria dos estudantes dedica-se atualmente somente a fazer o curso de graduação. Por fim, a maior parte dos estudantes dos dois grupos não tem experiência de trabalho com crianças pequenas, seja na educação formal ou informal.

Acerca das palavras evocadas, as associações com a palavra PROFESSOR produziram, entre os 68 estudantes da Unesp, 109 palavras diferentes para um total de 275 associações, enquanto que os 39 estudantes da UFMS produziram 77 palavras diferentes para um total de 162 associações. Percebese maior dispersão de associações entre os estudantes da UFMS. Para a composição do Núcleo Central (NC) e dos elementos periféricos (EP), levamos em conta as palavras que tiveram frequência maior que 4 e intermediária de 11 (EVOC, 2002). Com relação à ordem de evocação, foram consideradas como representações do NC as palavras com frequência maior que 8 e ordem média de evocação (OM) menor que 2,5.

As palavras que compuseram o provável NC PROFESSOR (Tabel I) dos estudantes da Unesp foram: ensinar, indicando a tarefa que cabe ao professor; escola, indicando o local onde ocorre o ensino; a atitude ou qualidade esperada daquele que ensina foi indicada pela palavra responsabilidade e a evocação daquele que ensina na escola com responsabilidade ocorreu por meio das palavras: educador e profissional.

No caso dos estudantes da UFMS, as palavras do provável NC PROFESSOR referiram-se a educador e a qualidade que este deve apresentar na relação interpessoal com a criança: amigo.

Tabela I - Primeiro quadrante do r̃quadro das quatro casasò mostrando frequência e ordem das evocações induzidas pela palavra ñprofessorò nos grupos de estudantes da Unesp e da UFMS

\begin{tabular}{|c|c|c|c|c|c|c|}
\hline \multirow{7}{*}{ 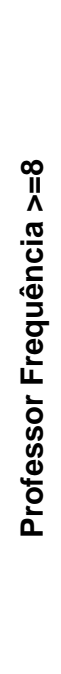 } & & $\begin{array}{l}\text { Segundo } \\
\text { quadrante - } \\
\text { Unesp } \\
\text { (provável } \\
\text { núcleo } \\
\text { central) }\end{array}$ & & $\begin{array}{c}\text { Primeiro } \\
\text { quadrante - } \\
\text { UFSM } \\
\text { (provável } \\
\text { núcleo } \\
\text { central) }\end{array}$ & & \\
\hline & Evocações & $f$ & OM & Evocações & $f$ & OM \\
\hline & Educador & 17 & 1,529 & Amigo & 13 & 2,462 \\
\hline & Ensinar & 20 & 2,200 & Educador & 15 & 1,333 \\
\hline & Escola & 9 & 2,222 & & & \\
\hline & Profissional & 9 & 2,222 & & & \\
\hline & $\begin{array}{l}\text { Responsabili- } \\
\text { dade }\end{array}$ & 12 & 2,083 & & & \\
\hline
\end{tabular}


As evocações dos estudantes da Unesp demonstram que o NC de sua RS está muito relacionado à identidade do professor dos anos iniciais do Ensino Fundamental. Os estudantes da UFMS, por sua vez, têm o que parece ser o NC de sua RS amparado na imagem do educador-amigo, o que parece demonstrar que a ausência de associações a outras qualidades ou aos saberes esperados no trabalho pedagógico com crianças pequenas indica uma ideia romântica e idealizada sobre ser professora de creche e pré-escola, além de se distanciar da figura do professor como profissional da área de educação. No caso da UFMS, ressaltamos que é necessário falar de NC com cautela devido ao número alto de palavras diferentes associadas à palavra professor. As outras etapas da pesquisa oferecerão dados para análises mais apuradas a este respeito.

No segundo quadrante (Tabela II), as associações dos estudantes da Unesp evidenciam características ou capacidades esperadas do professor: amigo, autoridade, inteligência e respeito. As associações presentes na segunda periferia indicam uma imagem de professor que não poderia prescindir da profissionalidade, da sensibilidade e da ética no trato com a criança. Entre os estudantes da UFMS, não foram encontradas associações para a palavra professor nesse quadrante.

Tabela II segundo quadrante do r̃quadro das quatro casasò mostrando frequência e ordem das evocações induzidas pela palavra ñprofessorò nos grupos de estudantes da Unesp e da UFMS

\begin{tabular}{|c|c|c|c|c|c|c|}
\hline \multirow{6}{*}{ 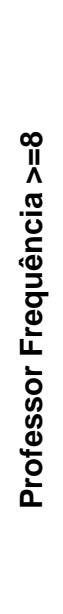 } & & $\begin{array}{c}\text { Segundo } \\
\text { quadrante - } \\
\text { Unesp } \\
\text { (Elementos } \\
\text { periféricos) }\end{array}$ & & $\begin{array}{l}\text { Segundo } \\
\text { quadrante - } \\
\text { UFSM } \\
\text { (elementos } \\
\text { periféricos }\end{array}$ & & \\
\hline & Evocações & $f$ & $\mathrm{OM}$ & Evocações & $f$ & $\mathrm{OM}$ \\
\hline & Amigo & 10 & 2,700 & & & \\
\hline & Autoridade & 10 & 2,900 & & Não houve & \\
\hline & Intelegência & 9 & 3,000 & & & \\
\hline & Respeito & 8 & 2,625 & & & \\
\hline
\end{tabular}

As associações mais próximas do NC (elementos periféricos) manifestas pelos estudantes da Unesp e a ausência encontrada entre os ingressantes da UFMS nos impelem a afirmar a possível centralidade da RS apontada antes (Tabela II). 
Menos frequentes (bem menores que 10), entre os estudantes da Unesp, foram evocadas as palavras: aluno, o espaço onde o educador exerce sua função: a aula e o objeto do seu trabalho: conhecimento, formação, educar, educação. Interessante a frequência baixa para a visão de criança pequena como aluno e a menção da sala de aula como único espaço das interações com a criança. Mas não parece interessante a baixa frequência em relação ao que é próprio da profissão docente. Outras associações se dão quanto a qualidades esperadas do educador: capacitado, dedicação, mestre, preparado, sabedoria. No caso dos estudantes da UFMS a palavra PROFESSOR foi associada com menos frequência a: capacitado, dedicação, educar, educação, ensinar e responsabilidade.

Os estudantes da UFMS, ao demonstrarem as associações anteriores com menor frequência, reforçam o NC educador-amigo. Uma ocorrência que nos chama a atenção é a utilização de educador, em detrimento da palavra professor, bem como seu uso no masculino, já que a grande maioria é do sexo feminino. Compreender as razões para tal ocorrência é tarefa para etapas seguintes da pesquisa.

Finalmente, no que concerne aos estudantes da Unesp, no último quadrante, com palavras menos frequentes e bem mais tardias, encontramos aspectos relacionados à relação do adulto com a criança: amor, paciência, carinhoso, exemplo, disciplina, importante ï e a palavra didática. Talvez essas evocações tardias revelem a incompreensão dos aspectos pedagógicos específicos do trabalho com crianças pequenas, justificada pela condição de ingressantes no curso, aliada ao senso comum de que, para ser professor na creche e na pré-escola, é necessário ser amoroso, paciente, exemplar, saber controlar as crianças e ter didática, compreendida como a capacidade de r̃manejaròbem a turma.

Os estudantes da UFMS fazem evocações que relacionam PROFESSOR às palavras aluno, atencioso, orientador, formador, paciência, respeito, conhecimento e profissional. Tais evocações tardias parecem confirmar, mais uma vez, o provável NC educador-amigo, mas contraditoriamente consideram aspectos relacionados à profissionalização, além de tomar a criança pequena como aluno, o que pode revelar a referência à criança e ao professor do Ensino Fundamental.

Em síntese, os estudantes da Unesp apresentam uma tendência de organização do NC de sua RS em torno da ideia-imagem do educador-profissional que ensina na escola com responsabilidade, autoridade, inteligência, amizade e respeito. Por sua vez, os estudantes da UFMS parecem organizar o NC de sua $\mathrm{RS}$ em torno da ideia-imagem do educador-amigo. Observa-se que os dois grupos preferem o termo reducadorò no lugar de ñprofessorò para se referir ao profissional que atua diretamente com a criança pequena, o que nos leva a concluir que os ingressantes de Pedagogia ainda não conseguem admitir um 
professor atuando com crianças em creches e pré-escolas, nem r̃se viramòcomo futuros professores de crianças pequenas no momento em que fizeram as evocações.

Sendo assim, ainda não encontramos, nesse grupo, RS sobre PROFESSOR que indiquem elaborações sobre o que é/como é ser professora de crianças pequenas, bem como sobre a especificidade do trabalho pedagógico na El, permitindo-nos afirmar que, em ambos os segmentos, ao se referirem ao professor, a imagem e o trabalho associado são os do professor de crianças do Ensino Fundamental, e as práticas são aquelas próprias dos primeiros anos/ séries deste nível de ensino. Ressaltamos que não podemos perder de vista que se trata de estudantes no início de sua formação em nível superior, além da circunstância de que a profissão de professor da El está em processo de constituição. Dessa maneira, a referência forte de professor como profissional é a do professor dos anos/séries iniciais do Ensino Fundamental.

Sobre o questionário-carta, no que diz respeito à questão que solicitava aos estudantes o apontamento da preferência pelo campo de trabalho, a tendência verificada foi diversificada. Os alunos da Unesp enfatizaram as três alternativas: ser professor universitário, professor de creche e pré-escola e professor de pré-escola (nessa ordem). Embora o magistério na El não seja a primeira opção, tal possibilidade se encontra presente entre os ingressantes de Pedagogia da Unesp, diferentemente dos estudantes da UFMS, que apontaram a preferência pela atuação em supervisão ou orientação, como professores das séries iniciais do Ensino Fundamental e em Educação Especial; no caso da última opção, cabe destacar que esta é uma área tradicionalmente bastante trabalhada e valorizada no curso de Pedagogia da UFMS. Os professores envolvidos com Educação Especial e educação social são aqueles com os quais os alunos simpatizam bastante, além do fato de serem estas as duas únicas áreas temáticas efetivamente estudadas e discutidas fora do espaço formal da sala de aula, o que pode ter influenciado a resposta nesse contexto. Por fim, podemos inferir que a El não se constitui preferencial como campo de trabalho no futuro.

Por outro lado, ao serem solicitados a se posicionar sobre a motivação na possibilidade de atuação futura na El, os dois grupos parecem motivados. A razão mais assinalada foi aquela relacionada ao fato de se ficar próximo da criança pequena e poder ajudá-la, o que nós inferimos como uma visão assistencialista da futura profissão e preconceituosa da criança, visto que pode indicar a compreensão atual do trabalho na El como maternagem e a própria criança como um ser incompleto. Sobre a minoria que respondeu não estar motivada para atuar na El, houve certa diferença entre os dois grupos; enquanto estudantes da Unesp enfatizaram a não identificação profissional e a falta de reconhecimento profissional como justificativa, os estudantes da UFMS mencionaram, além da falta de identificação profissional, a falta de preparo para o trabaIho com crianças pequenas. Os resultados obtidos nesta pergunta, se confrontados aos resultados sobre a preferência pelo campo de trabalho, já discutida 
antes, revelam que os estudantes dos dois grupos ainda não optaram pela atuação como professor de creche e pré-escola, colocando em dúvida a motivação destacada pela análise.

Quando estudantes dos dois grupos foram interrogados sobre onde/ em que pretendem basear seu trabalho de professora, marcaram como primeira opção a formação acadêmica, para, em seguida, indicar a observação do comportamento das crianças, o que denota expectativa de que o curso de formação inicial lhes dê a devida e adequada preparação para a vida profissional. Observamos que, na questão anterior, os estudantes não demonstraram a percepção de que o curso poderá lhes oferecer as condições de desenvolver saberes e capacidades, conhecimentos teóricos e práticos ligados ao trabalho de professora de crianças pequenas.

Ao inquiridos sobre a proximidade da profissão de professor de creche com outras profissões, a grande maioria de ambos os grupos respondeu que tal atividade está próxima do trabalho de babá. A justificativa dos estudantes para tal entendimento de sua futura profissão se referenda na compreensão de que babás e professores têm a tarefa de atender às necessidades básicas da criança. A mesma pergunta feita sobre o professor da pré-escola obteve resposta igual para os dois grupos de estudantes, sendo indicada como a profissão mais próxima a de professor do Ensino Fundamental, justificada pelo entendimento de que este é o período do início da alfabetização escolar.

Nas respostas a essas duas questões, temos presente a clássica dicotomia que envolve a El brasileira: a creche deve cuidar e, nesse sentido, a figura da babá é requisitada para exercer a maternagem, distanciando-se do professor com formação específica no atendimento na creche brasileira (0 e 3 anos de idade), enquanto a pré-escola deve educar... O cuidar comparece como suprimento das necessidades físicas, de saúde e algumas vezes afetivas, ao passo que o educar é visto como a escolarização precoce, a exemplo das rotinas e práticas próprias dos anos/séries iniciais do Ensino Fundamental. Ao serem perguntados sobre as tarefas da professora de creche, as atividades indicadas pelos dois grupos foram iguais, sendo as três recorrentes: dar carinho, brincar e organizar brincadeiras, nessa ordem para os dois grupos. No que diz respeito às tarefas da professora de pré-escola, houve alguma discrepância nas indicações. Enquanto os alunos da Unesp entendem que as atividades prioritárias seriam ensinar a ler e escrever, organizar reuniões de pais, além de observar e avaliar as crianças, os alunos do UFMS indicam as tarefas: atender crianças com necessidades especiais, organizar brincadeiras e, por último, ensinar a ler e escrever.

Os dados reforçam o NC das RS sobre o que é/como é ser professora de crianças pequenas, já mencionados, e caracterizam uma cisão sobre as tarefas de cuidar e educar na $\mathrm{El}$, atribuindo às creches ( 0 a 3 anos) as tarefas voltadas aos cuidados físicos e às pré-escolas ( $4 \mathrm{a} 5$ anos) o trabalho educativo 
reduzido à preparação para os anos posteriores da escolarização obrigatória. Esses resultados impõem às etapas posteriores deste estudo a investigação das prováveis diferenças de RS sobre ser professora da creche e professora da pré-escola e suas tarefas, além de pesquisar se, no decorrer do processo formativo na universidade, estas RS se transformam ou se mantêm resistentes, reforçando-se.

Os dois grupos foram perguntados sobre suas expectativas em relação à futura atuação no magistério na El. Suas repostas apresentaram aproximações e distanciamentos entre expectativas; enquanto na Unesp, os estudantes apontaram: ter paciência, ser carinhosa, saber sobre desenvolvimento infantil, saber alfabetizar, respeitar as diferenças individuais e manter os pais informados (todos com índices muito próximos); na UFMS citaram: ensinar hábitos de higiene, incentivar a criatividade das crianças, ter conhecimento sobre desenvolvimento infantil, gostar de criança e não demonstrar preferência ou rejeição por alguma criança.

As aproximações e distanciamentos observados não contradizem os resultados evidenciados até este momento no que concerne aos dois grupos. Há que se considerar as singularidades contextuais de cada grupo estudado, com destaque especial para a ênfase dada pelo curso de Pedagogia da UFMS à Educação Especial. As expectativas ressaltadas nos remetem aos dados apresentamos anteriormente, o que nos permite retornar à teoria das RS, para afirmar que as conversas, as crenças, as experiências e as ações valorizadas num determinado grupo, numa determinada cultura, condicionam a elaboração das RS. As RS têm o papel de transformar o que é estranho e distante em algo próximo e familiar, o que nos possibilita compreender a ñutilizaçãoòda referência de professor do Ensino Fundamental e suas tarefas, para organizar a RS de professor da El, com destaque ao professor da pré-escola e à imagem e tarefas da babá, para a professora da creche. Outros estudos recentes encontraram RS muito parecidas entre estudantes (GUIMARÃES, 2000; LIMA, FERNANDES e GONÇALVES, 2009; ENS; EYNG; GISI, 2009; HADDAD, 2009), o que exige não perder de vista que os dois grupos estão inseridos no contexto histórico-cultural brasileiro e se localizam em regiões com características sócio-político-econômicas e educacionais muito particulares.

Em síntese, podemos afirmar que os estudantes das duas universidadesï Unesp E UFMS ï têm perfis bastante parecidos, com exceção do fato de os ingressantes do curso de Pedagogia da UFMS serem cronologicamente um pouco mais velhos.

No que diz respeito à RS do que é/como é ser professora de crianças pequenas, os dois grupos não diferem de forma muito discrepante, apresentando distanciamentos e aproximações conforme os dados demonstraram.

A RS de ambos os grupos, sobre professora da creche e da pré-escola, apresentam aspectos equivocados acerca da especificidade do trabalho pe- 
dagógico da/na El, da identidade da professora que deve atuar nesse segmento educacional. No entanto, cabe reafirmar que a RS sobre professor dos estudantes da UFMS nos parece um pouco mais matizada pelo preconceito, pela visão ingênua, romantizada e menos amadurecida, do que a dos estudantes da Unesp.

\section{Palavras finais}

Cabe reiterar que encontramos, entre os estudantes das duas universidades, RS que não se adequam ainda ao perfil da professora de crianças pequenas e à concepção de criança/infância na contemporaneidade. Nem o professor escolar, segundo o modelo do Ensino Fundamental, nem o educadoramigo, que cuida de garantir apenas interesses e necessidades infantis, tampouco a criança inocente, que brinca despretensiosamente, correspondem ao conceito de professora e de criança, presentes na legislação brasileira e na literatura da área. Por fim, as RS apresentadas pelos estudantes estudados refletem o momento histórico brasileiro de construção da identidade da professora de creche e de pré-escola (HADDAD, 2009).

Nesse sentido, a RS que futuros professores de crianças pequenas têm do trabalho e de sua especificidade podem se constituir numa importante referência para a compreensão das motivações e resistências dos estudantes ingressantes no ensino superior, perante novos conhecimentos, reflexões, propostas e, de modo mais contundente, nos momentos de estágio. As contradições desveladas nas RS são aspectos favoráveis ao processo formativo em andamento, desde que interpretadas como RS elaboradas anteriormente ao ingresso no curso, por meio da experiência social e pessoal em contextos distintos.

Tendo em vista que estes ainda são dados e considerações preliminares da investigação, cabe enfatizar que o fato de serem estudadas as representações sociais de indivíduos que serão professores, no futuro, implica uma projeção das percepções atuais, ainda influenciadas pelas vivências dos estudantes em diferentes realidades sociais e culturais, bem como de formação de professores; no entanto, é perceptível que o senso comum visível nas RS de ambas as regiões pesquisadas está amparado nas mesmas bases de entendimento sobre o que é ser criança e sobre as práticas pedagógicas direcionadas a elas. É certo que as RS anteriores à formação para o exercício da profissão não garantem por si só a competência dos estudantes, tampouco dos profissionais; todavia, elas são essenciais como meios facilitadores na inserção acadêmica e profissional, o que nos impele a afirmar que conhecer essas RS e suas formas de elaboração auxilia, de maneira positiva, a elaboração e reelaboração dos processos de formação profissional e de construção da identidade profissional. 
A criança e o professor na Educação Infantil: representações de alunos do curso de Pedagogia

\section{Referências}

BAILLAUQUĖS, S. Trabalho das representações na formação dos professores. In: PAQUAY, L.; PERRENOUD, P.; ALTET, M.; CHARLIER, E. (Org.). Formando professores profissionais: quais estratégias? Quais competências? 2. ed. rev. Porto Alegre: Artmed, 2001, p. 37-54.

BARDIN, L. Análise de conteúdo. Lisboa: Edições 70, 1977.

BOLÍVAR, A. ¿De nobis ipsis silemusô Epistemología de la investigación biográfico-narrativa en educación. Revista Electrónica de Investigación Educativa, 4(1), 2002.

BRASIL. Conselho Nacional de Educação. Diretrizes Curriculares Nacionais para a Formação de Professores da Educação Básica, em nível superior, curso de licenciatura, de graduação plena. Parecer CNE/CP 009/2001. Brasília: DF, maio de 2001.

Conselho Nacional de Educação. Parecer CNE/CP 21/2001.

Lei de Diretrizes e Bases da Educação Nacional. Lei Federal n. 9.394/ 96, de 20 de dezembro de 1996.

CAMPOS, M. M.; FÜLLGRAF, J.; WIGGERS, V. A. Qualidade da Educação Infantil brasileira: alguns resultados de pesquisa. Cadernos de Pesquisa, v. 36, n. 127, p. 87-128, jan./abr. 2006.

CERISARAA. B.; CANDAL ROCHA, E. A.; SILVA FILHO, J. J. Educação Infantil: uma trajetória de pesquisa e indicações para a avaliação de contextos educativos. Zero a Seis - Revista Eletrônica, n. 15, jan/jun. 2007. Disponível em: http://www.ced.ufsc.br/ zeroseis/numero1.html. Acesso em: 1 jun. 2010.

CONNELLY, M.; CLANDININ, J. On narrative method, personal philosophy, and narrative unities in the story of teaching. Journal of Research in Science Teaching, 23(4), 1986, p. 293-310.

ENS, R. T.; EYNG, A. M.; GISI, M. L. Políticas de formação de professores e as representações de estudantes de Pedagogia e Biologia sobre o trabalho docente. NUANCES: estudos sobre Educação, 15(16), p.17-34, 2009.

GUIMARÃES, C. M. Representações Sociais e formação do professor préescolar. 2000. Tese (Doutorado em Educação) ï Faculdade de Filosofia e Ciências, Universidade Estadual Paulista, Marília, 2000.

HADDAD, L. Professora de El? Em busca do núcleo central da representação sociais a partir da análise das evocações livres. NUANCES: estudos sobre Educação, 16(17), p. 85-104, 2009.

LIMA, R. C. P.; FERNANDES, M. C. S. G.; GONÇALVES, M. F. C. Representações sociais de alunas de Pedagogia sobre o trabalho docente: Estágio e experiência. NUANCES: estudos sobre Educação, 16(17), p. 53-68, 2009. 
Célia M. Guimarães ñ Sílvia A. Rodrigues ñ Claudia C. Garcia Piffer

MACHADO, M. L. A. Criança pequena, El e formação dos profissionais. Perspectiva. Florianópolis, v. 17, n. Especial, p. 85-98. jul./dez. 1999.

MOSCOVICI, S. A representação social da psicanálise. Tradução: Álvaro Cabral. Rio de Janeiro: Zahar, 1978.

The phenomenon of social representations. In: R. FARR; S. MOSCOVICI. (Ed.), Social Representations. Cambridge: Cambridge University Press, 1984, p. 3-70.

Representações sociais. Investigações em Psicologia Social. Petrópolis: Vozes, 2003.

OLIVEIRA-FORMOSINHO, J. et al. (Org.). Pedagogia(s) da infância ï dialogando com o passado-construindo o futuro. Porto Alegre: Artmed, 2007.

REIS, P. As narrativas na formação de professores e na investigação em educação. NUANCES: estudos sobre Educação, 15(16), p. 17-34, 2008.

SZYMANSKI, H. A entrevista reflexiva. Revista Psicologia da Educação, 10/ 11, 193-215, 2001.

VERGÉS, P. Ensemble de Programmes Permettant Läannalyse des Evocations $\tilde{n}$ EVOC 2002. Manuel, version 5 avril 2002.

\section{Notas}

1 O termo professora será utilizado, ao longo do texto, considerando os resultados recorrentes nas pesquisas da área, indicando a crescente feminilização do magistério, nesse nível de ensino da educação básica brasileira (CAMPOS; FÜLLGRAF; WIGGERS, 2006).

2 Siglas: Unesp Universidade Estadual Paulista; UFMS ï Universidade Federal do Mato Grosso do Sul.

3 Trabalho realizado a partir de questionário similar elaborado pelas professoras Maria Helena Cordeiro, da Universidade do Vale do Itajaí ï Univali ï e Lenira Haddad, da UFAL, no ano de 2008.

${ }^{4}$ A Resolução CNE/CP n. 1, de 15/5/2006, institui as Diretrizes Curriculares Nacionais para os cursos de graduação em Pedagogia. A Resolução CNE/CP n. 001/2002 estabelece as Diretrizes Curriculares Nacionais para a Formação de Professores da Educação Básica, em nível superior, regulamentando os cursos de licenciatura de graduação plena.

${ }^{5} \mathrm{O}$ uso dos termos creche e pré-escola, conforme a LDB/96, considera a especificidade das faixas etárias atendidas e a continuidade das ações de cuidado e educação, no atendimento à criança pequena ( 0 a 5 anos).

${ }^{6}$ Estudantes do período diurno (28 alunos) e noturno (40 alunos) da Faculdade de Ciências e Tecnologia da Universidade Estadual Paulista, Campus de Presidente Prudente-FCT/UNESPBrasil. Este é um dos 23 campi da Unesp, localizados no interior do Estado de São Paulo e na capital.

${ }^{7}$ Estudantes do período vespertino (39 alunos) da Universidade Federal do Mato Grosso do Sul ï CPAN/UFMS ï Brasil. Esta unidade universitária está localizada na cidade de Corumbá-MS, região de fronteira com a Bolívia, e se define como campus do Pantanal. 
A criança e o professor na Educação Infantil: representações de alunos do curso de Pedagogia

\section{Correspondência}

Célia Maria Guimarães ï Rua José Carmelo Zaupa, 41 ï Vila Maristela ï CEP 19020-310.

São Paulo, Brasil.

E-mail: cmgui@fct.unesp.br

Recebido em 10 de março de 2011

Aprovado em 21 de junho de 2011 